\title{
Melanosis coli in a child of four years
}

Barrie A. Price

M.B. B.S.

\author{
Richard E. C. Collins \\ M.B., F.R.C.S.
}

\author{
Malcolm D. FARLeY \\ M.B., M.R.C.Path.
}

\begin{abstract}
Departments of Surgery and Pathology, Isle of Thanet District Hospital, Margate Wing
\end{abstract}
\begin{abstract}
Summary
A case of melanosis coli in a girl of 4 years is described. The condition is usually considered a disease of the ageing bowel. In this case there was a history of constipation, and anthracene abuse.
\end{abstract}

\section{Case report}

A 4-year-old female presented with a history of faecal soiling and constipation for 18 months. Her bowels were opened every 4 to 5 days during this time but a regular bowel habit had never been established since birth. She had been taking Senokot syrup (1.4 mg sennocides A and B per $\mathrm{ml}) 5 \mathrm{ml}$ at night for 12 months and Dorbanex syrup (danthron $25 \mathrm{mg}$ and poloxalkol $200 \mathrm{mg} / 5 \mathrm{ml}) 5 \mathrm{ml}$ at night 4 times weekly for 6 months before being seen. There was no relevant past medical history. Abdominal examination was normal, but rectal examination was resisted by the patient.

She was admitted for examination under anaesthesia which revealed a tight anal band at the mucocutaneous junction. Manual dilatation of the anus was performed (Clayden and Lawson, 1976). Her symptoms were no better 4 months later and she was continuing to take Dorbanex at the same dosage. She was admitted for repeat manual dilatation of the anus and a rectal biopsy to exclude Hirschsprung's disease. Sigmoidoscopy appearances were normal, but histology showed evidence of melanosis coli. Ganglion cells were present.

Four months following her repeat anal stretch she is opening her bowels daily or every other day with an occasional $5 \mathrm{ml}$ dose of Dorbanex syrup every 2-3 weeks.

\section{Discussion}

Melanosis coli has been a curiosity for 150 years since Cruveilhier's original description (1829).
Virchow (1847) gave the name melanosis coli to the condition, and presented a personally labelled specimen to the Pathologic Institute in Berlin. Theodore Williams (1867) observed pigmentation of the rectal mucosa in a woman with a rectal prolapse. The first sigmoidoscopic appearance was described by Pick (1911). Figures between series vary too widely for a precise assessment of incidence. Roden (1940) found incidences of $4.3 \%$ and $11 \%$ ip his 2 series of post-mortem examinations. In the firs? study, the condition was not particularly sough after, but in the second it was meticulously looke for. No age group is exempt over 20 years, but mainly the $40-60$-year group is affected. Sex incidence is equal in most series. Melanosis coli has been found above and below malignant lesions (Stewart and Hickman, 1931). A definite relationship is denied by most workers, however.

Pigment is distributed equally throughout the colon, but some authors have noted greater deposition in the rectum and caecum with lessening degrees in the flexures and transverse colon. There is a marked cut-off at the ileocaecal and anorectal junctions although occasionally microscopic pigment has been found in the terminal ileum and mesenteric nodes. A lymphatic block is postulated for this but Roden (1940) suggested a functional rather than an anatomical block.

Macroscopically, dusky-brown through to inkyblack pigmented areas are seen interlaced with yellow striae thought to be of lymphatic origin. It has been described as reminiscent of toad's back, nutmeg cross-section, alligator skin, roof of dog's mouth or chow dog's tongue. In mild cases, the mucosa may appear normal. Microscopically, the epithelium is free of pigment, the melanin being situated in mononuclear cells as granules 1-5 $\mu$ diameter with an internal structure of coarse and fine particles and a network of tangled membranes 


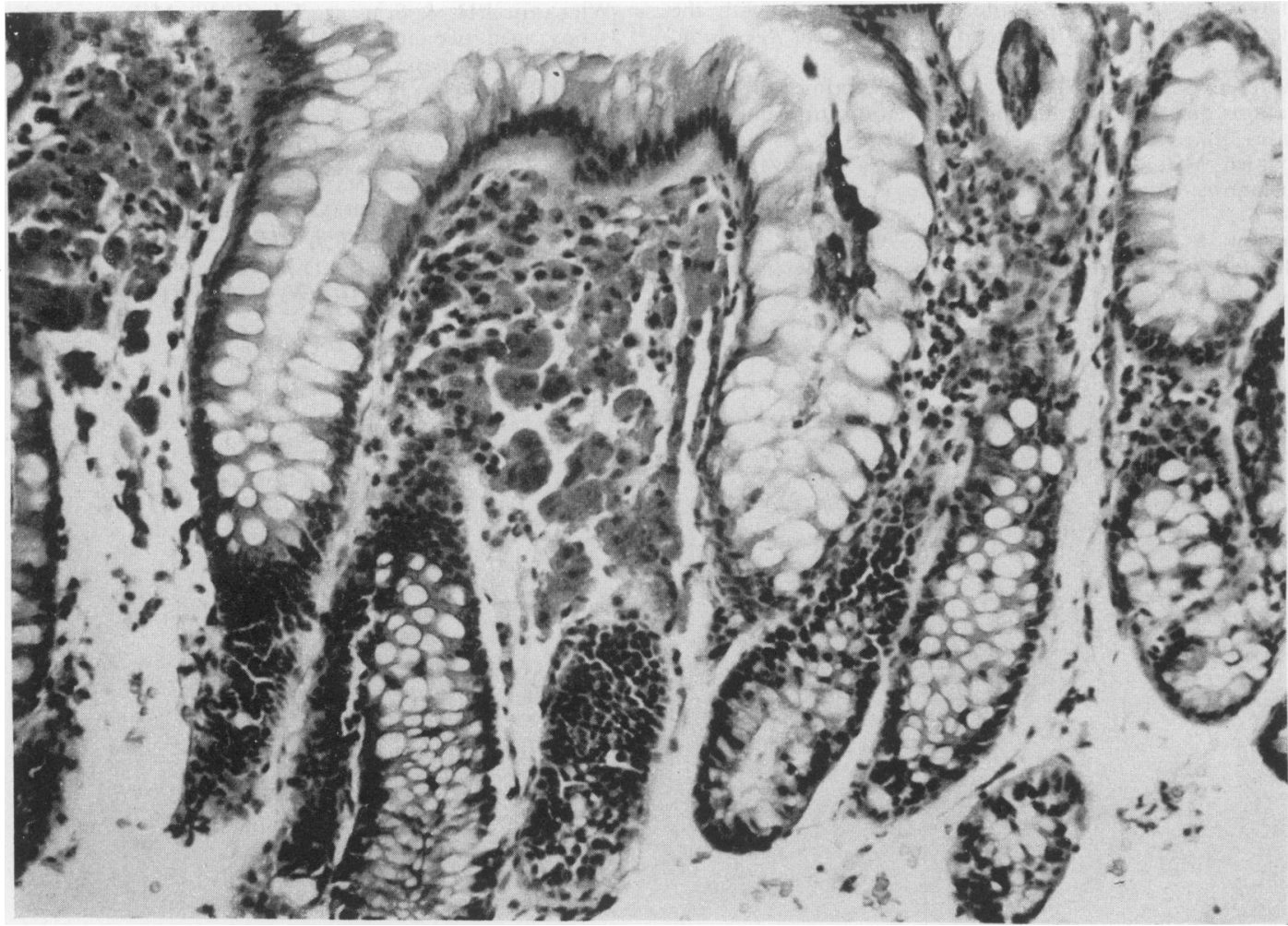

FIG. 1. Rectal biopsy showing melanosis coli $(\mathrm{HE}, \times 95)$.

similar to disordered cristae of adjacent mitochondria (Schrodt, 1963). Biochemically, the pigment is thought to be a melanin with less nitrogen than that of skin or hair. Lipofuchsin, pigment containing iron or heavy metals, breakdown products of myoglobin and chlorophyll have also been suggested.

Bartle (1928) was the first to suggest the association between melanosis coli and the anthracene cathartics. Constipation is also a strong factor and further studies have supported these views (Speare, 1951; Wittoesch, Jackman and McDonald, 1958; Zobel and Susnow, 1935; Bockus, Willard and Bank, 1933). The average time for appearance of melanosis using anthracene derivatives is approximately 12 months. It usually disappears 4 to 12 months after discontinuing the drugs (Wittoesch et al., 1958). The present case supports these findings. Melanosis coli is considered a condition of the ageing bowel, the only previous report in a child under 10 years was by Willard and Schutt (1938). The authors believe that melanosis coli may be more common in children than has been supposed in the past, especially if constipation and the habitual use of anthracenes are present.

\section{Acknowledgments}

We wish to thank Mrs Susan Cover and Mrs Enid Hawley, librarians Canterbury and Thanet Hospitals, and Mrs Beryl Price for typing the manuscript. Also Mr E. W. Spice, F.I.M.L.S., for technical assistance.

\section{References}

Bartle, H.J. (1928) The sigmoid. Anatomy, physiology, examination and pathology. Medical Journal and Record. $127,521$.

Bockus, H.L., Willard, J.H. \& Bank, J. (1933) Melanosis coli. The etiologic significance of the anthracene laxatives. A report of forty-one cases. Journal of the American Medical Association. 101, 1.

Clayden, G.S. \& LAwson, J.O.N. (1976) Investigation and management of long standing chronic constipation in childhood. Archives of Disease in Childhood, 51, 918.

Cruveilhier, J. (1829) Cancer avec mélanosis. In: Anatomie Pathologique du Corps Humain. Paris, Baillière, 19, 6.

Pick, L. (1911) Ueber die Melanose der Dickdarmschleim haut. Berliner klinische Wochenschrift, 19, 840.

Roden, D. (1940) Melanosis coli. A pathological study: its experimental production in monkeys. Irish Journal of Medical Science, 6, 654. 
Schrodt, G.R. (1963) Melanosis coli. A study with the electron microscope. Diseases of the Colon and Rectum, 6, 277.

SpeARe, G.S. (1951) Melanosis coli. Experimental observations on its production and elimination in twenty-three cases. American Journal of Surgery, 82, 631.

Stewart, M.J. \& Hickman, E.M. (1931) Observations of melanosis coli. Journal of Pathology and Bacteriology, 34, 61 .

Virchow, R. (1847) Die pathologischen Pigmente. Virchows Archiv fur pathologische Anatomie und Physiologie und für klinische Medizin, 1, 379.
Willard, J.H. \& SchutT, T.J. (1938) Melanosis coli in a boy aged two and one half years. American Journal of $\bar{D}$ Digestive Diseases, 5, 693.

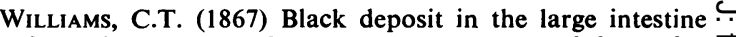
from the presence of mercury. Transactions of the Patho- $\overrightarrow{\overrightarrow{7}}$ logical Society of London, 18, 111.

Wittoesch, J.H., Jackman, R.J. \& McDonald, J.R. (1958) Melanosis coli. General review and study of 887 cases. Diseases of the Colon and Rectum, 1, 172.

Zobel, A.J. \& SuSNow, D.A. (1935) Melanosis coli. Its clinical significance. Archives of Surgery, 30, 974. 